\title{
Investigation of Gamma and Neutron Shielding Parameters for Borate Glasses Containing $\mathrm{NiO}$ and $\mathrm{PbO}$
}

\author{
Vishwanath P. Singh ${ }^{1,2}$ and N. M. Badiger ${ }^{1}$ \\ ${ }^{1}$ Department of Physics, Karnatak University, Dharwad 580003, India \\ ${ }^{2}$ Health Physics Section, Kaiga Atomic Power Station-3\&4, NPCIL, Karwar 581400, India \\ Correspondence should be addressed to Vishwanath P. Singh; kudphyvps@rediffmail.com
}

Received 18 January 2014; Accepted 5 March 2014; Published 23 April 2014

Academic Editor: Ali Hussain Reshak

Copyright (c) 2014 V. P. Singh and N. M. Badiger. This is an open access article distributed under the Creative Commons Attribution License, which permits unrestricted use, distribution, and reproduction in any medium, provided the original work is properly cited.

\begin{abstract}
The mass attenuation coefficients, $\mu / \rho$, half-value layer, HVL, tenth-value layer, TVL, effective atomic numbers, $Z_{P I e f f}$, and effective electron densities, $N_{e, \text { eff }}$, of borate glass sample systems of $(100-x-y) \mathrm{Na}_{2} \mathrm{~B}_{4} \mathrm{O}_{7}: x \mathrm{PbO}: y \mathrm{NiO}$ (where $x$ and $y=0,2,4,6,8$, and 10 weight percentage) containing $\mathrm{PbO}$ and $\mathrm{NiO}$, with potential gamma ray and neutron shielding applications, have been investigated. The gamma ray interaction parameters, $\mu / \rho$, HVL, TVL, $Z_{P I \text { eff }}$, and $N_{e \text {,eff }}$, were computed for photon energy range $1 \mathrm{keV}-100 \mathrm{GeV}$. The macroscopic fast neutron removal cross-sections $\left(\Sigma_{R}\right)$ have also been calculated. Appreciable variations were noted for all the interaction parameters by varying the photon energy and the chemical composition of the glass samples. The better shielding properties of borate glass samples containing $\mathrm{PbO}$ were found. These results indicated that borate glass samples are a good radiation shielding material.
\end{abstract}

\section{Introduction}

Interaction of energetic radiations $\mathrm{X} / \gamma$-ray and neutron with the material is essential in radiation technologies, medical, nuclear engineering, agriculture, space technology, industries, and other shielding applications. Transparent radiation shielding materials have been an interesting area in nuclear engineering to provide the adequate radiation protection as well as visibility through it. Glasses are found to perform the double functions of being transparent to visible light and absorbing the radiations, thus providing radiation shielding to the observer. The silicate glasses are found to be the most commonly commercial glasses owning to ease of fabrication and excellent transparency to the visible light [1]. The transparent property of the glass makes it useful for optical windows in nuclear reactors and isotope technology centers. The optical windows play a crucial role in operation and maintenance of nuclear facilities for complete visual inspection without radiation exposure.

Lead and lead glasses are easily available for shielding of the gamma rays and neutrons due to high densities and atomic numbers [2]. The high atomic number $(Z)$ offers large gamma ray interaction cross-section for gamma rays and density plays vital role in neutron interaction. Nowadays, bismuth (Bi) and barium $(\mathrm{Ba})$ are playing an analogous role in radiation shielding by replacing lead. The glasses containing low $Z$ elements ( $\mathrm{H}, \mathrm{Li}, \mathrm{B}, \mathrm{C}$, etc.) are another group of the glasses required for neutron radiation shielding produced specially in nuclear reactors and accelerators. It has been found that gamma photon in reactor is in range of 0.10 to $10 \mathrm{MeV}$ and prompt neutron energy spectrum ranges from 0.18 to $12 \mathrm{MeV}$ with average neutron energy 1 to $2 \mathrm{MeV}$ during uranium fission [3]. Therefore boron containing glass materials are found to be a potential candidate for neutron radiation shielding.

The absorption of gamma ray is being represented by the mass attenuation coefficients, atomic cross-sections, effective atomic numbers, and effective electron densities. The attenuation coefficient is defined as the probability of radiation interaction with a material per unit length [4]. The effective atomic number is a convenient parameter for evaluation of gamma ray interaction for a compound or mixtures. The other important parameter for interaction is an electron density which is defined as the electrons per unit mass 
TABLE 1: Borate glass samples containing $\mathrm{PbO}$ and $\mathrm{NiO}$ for shielding.

\begin{tabular}{lcccc}
\hline \multirow{2}{*}{ Glass sample } & \multirow{2}{*}{ Densities $\left(\mathrm{g} \mathrm{cm}^{-3}\right)$} & \multicolumn{3}{c}{ Weight percentage } \\
& & $\mathrm{Na}_{2} \mathrm{~B}_{4} \mathrm{O}_{7}$ & $\mathrm{PbO}$ & $\mathrm{NiO}$ \\
\hline $\mathrm{S}_{1}$ & $2.64 \pm 0.02$ & 100 & 0 & 0 \\
$\mathrm{~S}_{2}$ & $2.67 \pm 0.04$ & 90 & 0 & 10 \\
$\mathrm{~S}_{3}$ & $2.67 \pm 0.05$ & 90 & 2 & 8 \\
$\mathrm{~S}_{4}$ & $2.71 \pm 0.03$ & 90 & 4 & 6 \\
$\mathrm{~S}_{5}$ & $2.73 \pm 0.02$ & 90 & 6 & 4 \\
$\mathrm{~S}_{6}$ & $2.75 \pm 0.02$ & 90 & 8 & 2 \\
$\mathrm{~S}_{7}$ & $2.78 \pm 0.01$ & 90 & 10 & 0 \\
\hline
\end{tabular}

of the absorber. Mass attenuation coefficients of elements, compounds, and mixtures are taken from standard tables [5] developed as XCOM program at energies $1 \mathrm{keV}$ to $100 \mathrm{GeV}$. The XCOM program has been converted to user-friendly windows platform WinXcom [6].

Various investigators have reported gamma ray interaction parameters of phosphate, lead, bismuth, silicate, and flyash glasses [2, 7-11]. $\mathrm{NiO}$ is being used for making smoky colored glasses and for decolouring lead crystal glasses [12]. The gamma ray attenuation coefficients of borate glasses are found for 1173 and $1332 \mathrm{keV}$ [13]. However detailed study on gamma ray and neutron interaction for the colored borate glasses containing $\mathrm{NiO}$ is not found in the literatures. This encouraged us to investigate the gamma and neutron interaction parameters of borate glasses, potential shielding materials. Therefore, we have calculated the mass attenuation coefficients, $\mu / \rho$, half-value layer, HVL, tenth-value layer, TVL, effective atomic numbers, $Z_{P I \text { eff }}$, and effective electron densities, $N_{e \text {,eff }}$, of borate glass samples containing $\mathrm{PbO}$ and $\mathrm{NiO}$ given in Table 1 . The study shall be useful for shielding against gamma ray and neutron applications.

\section{Theoretical Background and Computational Work}

2.1. Gamma Ray Interaction Parameters. The compositions of borate glass samples containing $\mathrm{PbO}$ and $\mathrm{NiO}$ are given in Table 1. The transmission of gamma ray is dependent upon the material thickness, $t$, and linear attenuation coefficient, $\mu$. The $\mu$ value is a parameter which is dependent upon the absorber density, its atomic number, and energy of incident photon. The linear attenuation coefficients of the borate glass samples are calculated by multiplication of mass attenuation coefficients, $\mu / \rho$, and density. The $\mu / \rho$ values of the borate glasses are calculated by mixture rule $\left((\mu / \rho)_{\text {glass }}=\right.$ $\left.\sum_{i}^{n} w_{i}(\mu / \rho)_{i}\right)$, where $w_{i}$ is the proportion by weight and $(\mu / \rho)_{i}$ is mass attenuation coefficient of the $i$ th element by using WinXcom [6]. The quantity $w_{i}$ is given by $w_{i}=n_{i} A_{i} / \sum_{j}^{n} n_{j} A_{j}$ with condition $\sum_{i}^{n} w_{i}=1$, where $A_{i}$ is the atomic weight of the $i$ th element and $n_{i}$ is the number of formula units in the compounds. The half-value layer, HVL $(\mathrm{HVL}=0.6932 / \mu)$, and tenth-value layer, TVL $(\mathrm{TVL}=2.303 / \mu)$, are inversely proportional to $\mu$ values.
The effective atomic numbers $\left(Z_{P I \text { eff }}\right)$ for total photon interaction are given by [14]

$$
Z_{P I \text { eff }}=\frac{\sum_{i} f_{i} A_{i}(\mu / \rho)_{i}}{\sum_{j} f_{j}\left(A_{j} / Z_{j}\right)(\mu / \rho)_{j}},
$$

where $f_{i}$ is molar fraction in the mixture, $\mu$ is linear attenuation coefficient, $\rho$ is density, $\mu / \rho$ is mass attenuation coefficient, $A$ is atomic weight, $Z$ is atomic number, and the ratio, $A / Z$, between the atomic mass and the atomic number is approximately constant. The electron density is given by $N_{e, \text { eff }}=N_{A} Z / A$ which is generalized as

$$
N_{e, \mathrm{eff}}=N_{A} \frac{n Z_{P I \mathrm{eff}}}{\sum_{i} n_{i} A_{i}}=N_{A} \frac{Z_{P I \mathrm{eff}}}{\langle A\rangle},
$$

where $n_{i}$ is the number of atoms of the $i$ th constituent element, $n$ is the total number of atoms, and $\langle A\rangle$ is average atomic mass of the glass samples.

2.2. Macroscopic Fast Neutron Removal Cross-Sections. The effective removal cross-section of compounds and homogenous mixtures is calculated using the value of $\Sigma_{R}\left(\mathrm{~cm}^{-1}\right)$ or $\Sigma_{R} / \rho\left(\mathrm{cm}^{2} / \mathrm{g}\right)$ of the elements in the compounds by mixture rule [4]. The detailed calculation procedure for $\Sigma_{R}$ can be found various recent literatures for alloys [15], fly-ash brick materials [16], bismuth borosilicate glasses [17], oxide dispersion strengthened steels [18] and building materials [19]. The $\Sigma_{R} / \rho$ values of elements have been taken from Kaplan and Chilton $[20,21]$.

\section{Results and Discussion}

In the present investigation, the mass attenuation coefficients, $\mu / \rho$, half-value layer, HVL, tenth-value layer, TVL, effective atomic numbers, $Z_{P I \text { eff }}$, and effective electron densities, $N_{e \text {,eff }}$, of borate glasses containing $\mathrm{PbO}$ and $\mathrm{NiO}$ were calculated. The variation of $\mu / \rho, \mathrm{HVL}, \mathrm{TVL}, Z_{\text {PI eff }}$, and $N_{e \text {,eff }}$ is shown in Figures 1-5 respectively. The macroscopic fast neutron removal cross section of the borate glasses is given in the Table 5.

3.1. Mass Attenuation Coefficients. The variation of mass attenuation coefficients, $\mu / \rho$, of the borate glass samples with photon energy ranging from $1 \mathrm{keV}$ to $100 \mathrm{GeV}$ is shown in Figure 1. From Figure 1 one can observe that the $\mu / \rho$ values of the borate glass samples are very high in photoelectric absorption region, reduce gradually, and become lowest in Compton scattering region. After it again starts increasing and becomes constant at around photon energy of $100 \mathrm{MeV}$ in pair production region, various peaks in $\mu / \rho$ values are observed for the glasses in photoelectric absorption region due to $K$-edge absorption $(1.072,8.333$, and $8.8 \mathrm{keV}), L$-edge absorption (1.008, 1.586, 1.52, and $1.304 \mathrm{keV})$, and $M$-edge absorption $(3.851,3.554,3.066,2.586$, and $2.484 \mathrm{keV})$. The $K$, $L$, and $M$ absorption energy values of the constituent elements $(\mathrm{Na}, \mathrm{Ni}$, and $\mathrm{Pb})$ are given in Table 2 . The borate glass sample containing maximum $\mathrm{PbO}$ composition $\left(\mathrm{S}_{7}\right)$ shows 
TABle 2: Photon energies (in $\mathrm{keV}$ ) of absorption edges of $K, L$, and $M$.

\begin{tabular}{|c|c|c|c|c|c|c|c|c|c|c|}
\hline \multirow{3}{*}{ Element } & \multirow{3}{*}{$Z$} & \multicolumn{9}{|c|}{ Energy (keV) } \\
\hline & & \multirow{2}{*}{ K } & \multicolumn{3}{|c|}{$L$} & \multicolumn{5}{|c|}{$M$} \\
\hline & & & $L_{1}$ & $L_{2}$ & $L_{3}$ & $M_{1}$ & $M_{2}$ & $M_{3}$ & $M_{4}$ & $M_{5}$ \\
\hline B & 5 & - & - & - & - & - & - & - & - & - \\
\hline $\mathrm{O}$ & 8 & - & - & - & - & - & - & - & - & - \\
\hline $\mathrm{Na}$ & 11 & 1.072 & - & - & - & - & - & - & - & - \\
\hline $\mathrm{Ni}$ & 28 & 8.333 & 1.008 & - & - & - & - & - & - & - \\
\hline $\mathrm{Pb}$ & 82 & 8.800 & 1.586 & 1.520 & 1.304 & 3.851 & 3.554 & 3.066 & 2.586 & 2.484 \\
\hline
\end{tabular}

TABLE 3: Effective atomic numbers $\left(Z_{P I \text { eff }}\right)$ of borate glasses at different energies $(\mathrm{MeV})$ for total photon interaction.

\begin{tabular}{lcccccccccccc}
\hline Glass sample & $\langle Z\rangle$ & $\begin{array}{c}Z_{\text {PIeff }} \\
\text { lower }\end{array}$ & $\begin{array}{l}Z_{\text {PIeff }} \\
\text { upper }\end{array}$ & $10^{-3}$ & $10^{-2}$ & $10^{-1}$ & $10^{0}$ & $\begin{array}{c}Z_{\text {PIeff }} \\
10^{1}\end{array}$ & $10^{2}$ & $10^{3}$ & $10^{4}$ & $10^{5}$ \\
\hline $\mathrm{S}_{1}$ & 7.47 & 7.54 & 9.03 & 7.69 & 9.02 & 7.60 & 7.54 & 7.66 & 7.92 & 7.95 & 7.94 & 7.94 \\
$\mathrm{~S}_{2}$ & 8.00 & 7.75 & 14.31 & 8.38 & 14.04 & 8.20 & 7.75 & 7.99 & 8.49 & 8.54 & 8.53 & 8.53 \\
$\mathrm{~S}_{3}$ & 8.00 & 7.84 & 21.46 & 8.47 & 15.25 & 12.48 & 7.86 & 8.24 & 9.08 & 9.15 & 9.14 & 9.14 \\
$\mathrm{~S}_{4}$ & 8.02 & 7.95 & 27.76 & 8.56 & 16.52 & 16.30 & 7.96 & 8.49 & 9.66 & 9.75 & 9.74 & 9.73 \\
$\mathrm{~S}_{5}$ & 8.04 & 8.03 & 33.30 & 8.65 & 17.84 & 19.71 & 8.07 & 8.74 & 10.23 & 10.35 & 10.33 & 10.32 \\
$\mathrm{~S}_{6}$ & 8.06 & 8.12 & 38.22 & 8.74 & 19.22 & 22.79 & 8.18 & 8.99 & 10.79 & 10.93 & 10.91 & 10.90 \\
$\mathrm{~S}_{7}$ & 8.08 & 8.22 & 42.86 & 8.85 & 20.81 & 25.76 & 8.29 & 9.25 & 11.39 & 11.55 & 11.52 & 11.52 \\
\hline
\end{tabular}

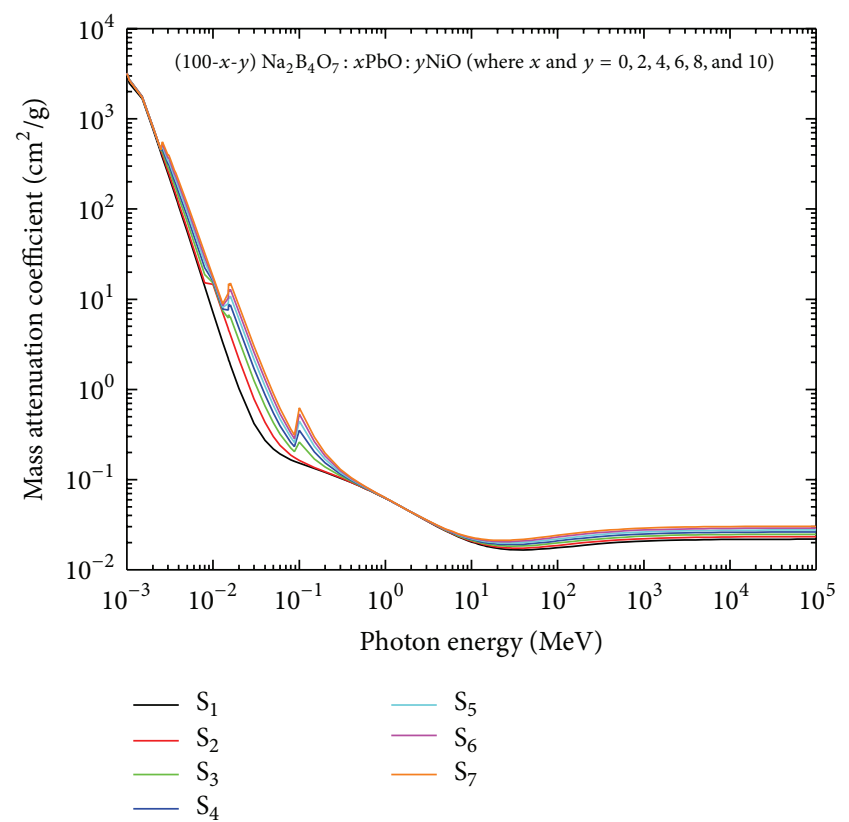

FIGURE 1: Variation of mass attenuation coefficients of the borate glasses containing $\mathrm{PbO}$ and $\mathrm{NiO}$ with photon energy for range $1 \mathrm{keV}$ to $100 \mathrm{GeV}$.

multiple peaks due to $K, L$, and $M$ absorption edges whereas borate glass sample without $\mathrm{PbO}$ and $\mathrm{NiO}\left(\mathrm{S}_{1}\right)$ is found to be with single peak due to $\mathrm{Na}$ element. These variations can be explained by the partial photon interactions such as photoelectric absorption for low-energy, Compton scattering for intermediate-energy, and pair production (nuclear and electric) for high-energy regions.

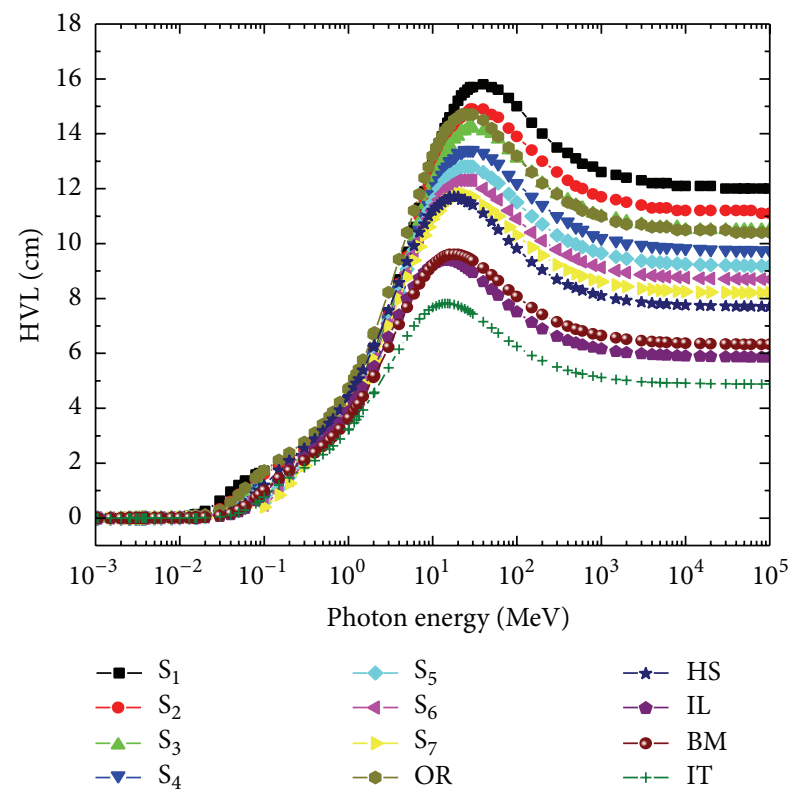

FIGURE 2: Variation of half-value layer of the borate glasses containing $\mathrm{PbO}$ and $\mathrm{NiO}$ with photon energy for range $1 \mathrm{keV}$ to $100 \mathrm{GeV}$.

Initially at $1 \mathrm{keV}$ energy, the values of $\mu / \rho$ are very large (order of $10^{3}$ ) which decrease sharply. At low-energy range $(0.01 \mathrm{MeV}<E<0.1 \mathrm{MeV})$, the maximum value of $\mu / \rho$ was found. The values of $\mu / \rho$ of all the borate glass samples become of order of $10^{-1}$ as photon energy reaches $100 \mathrm{keV}$. Hence the $\mu / \rho$ values decrease rapidly in low-energy region. This shows the dominance of photoelectric absorption in lowphoton energy region. It can also be observed that there is 
TABLE 4: Effective electron densities $\left(N_{e, \text { eff }}\right)$ of borate glasses at different energies $(\mathrm{MeV})$ for total photon interaction.

\begin{tabular}{lcccccccccccc}
\hline Glass sample & $\langle N\rangle$ & $\begin{array}{l}N_{e, \text { eff }} \\
\text { lower }\end{array}$ & $\begin{array}{l}N_{e, \text { eff }} \\
\text { upper }\end{array}$ & $10^{-3}$ & $10^{-2}$ & $10^{-1}$ & $10^{0}$ & $N_{e, \text { eff }} \times 10^{23}$ & $10^{2}$ & $10^{3}$ & $10^{4}$ & $10^{5}$ \\
\hline $\mathrm{S}_{1}$ & 2.92 & 3.05 & 3.65 & 3.11 & 3.65 & 3.07 & 3.05 & 3.10 & 3.20 & 3.21 & 3.21 & 3.21 \\
$\mathrm{~S}_{2}$ & 3.04 & 3.04 & 5.61 & 3.28 & 5.50 & 3.21 & 3.04 & 3.13 & 3.33 & 3.35 & 3.34 & 3.34 \\
$\mathrm{~S}_{3}$ & 3.00 & 3.04 & 8.32 & 3.28 & 5.91 & 4.84 & 3.05 & 3.20 & 3.52 & 3.55 & 3.54 & 3.54 \\
$\mathrm{~S}_{4}$ & 2.97 & 3.04 & 10.60 & 3.28 & 6.32 & 6.24 & 3.05 & 3.25 & 3.70 & 3.73 & 3.73 & 3.72 \\
$\mathrm{~S}_{5}$ & 2.94 & 3.03 & 12.58 & 3.27 & 6.74 & 7.45 & 3.05 & 3.30 & 3.86 & 3.91 & 3.90 & 3.90 \\
$\mathrm{~S}_{6}$ & 2.91 & 3.03 & 14.25 & 3.26 & 7.16 & 8.50 & 3.05 & 3.35 & 4.02 & 4.07 & 4.07 & 4.06 \\
$\mathrm{~S}_{7}$ & 2.88 & 3.02 & 15.78 & 3.25 & 7.65 & 9.48 & 3.05 & 3.40 & 4.19 & 4.25 & 4.24 & 4.24 \\
\hline
\end{tabular}

TABLE 5: Macroscopic fast neutron removal cross-section of the borate glasses.

(a)

\begin{tabular}{lcccccccr}
\hline Ele. & \multicolumn{2}{c}{$\mathrm{S}_{1}$} & \multicolumn{2}{c}{$\mathrm{S}_{2}$} & \multicolumn{2}{c}{$\mathrm{S}_{3}$} & $\mathrm{~S}_{4}$ \\
& $\mathrm{PD}$ & $\Sigma_{R}\left(\mathrm{~cm}^{-1}\right)$ & $\mathrm{PD}$ & $\Sigma_{R}\left(\mathrm{~cm}^{-1}\right)$ & $\mathrm{PD}$ & $\Sigma_{R}\left(\mathrm{~cm}^{-1}\right)$ & $\mathrm{PD}$ & $\Sigma_{R}\left(\mathrm{~cm}^{-1}\right)$ \\
\hline $\mathrm{Na}$ & $6.03 E-01$ & $2.06 E-02$ & $5.86 E-01$ & $2.00 E-02$ & $5.77 E-01$ & $1.97 E-02$ & $5.77 E-01$ & $1.97 E-02$ \\
$\mathrm{~B}$ & $5.67 E-01$ & $3.26 E-02$ & $5.51 E-01$ & $3.17 E-02$ & $5.43 E-01$ & $3.12 E-02$ & $5.42 E-01$ & $3.12 E-02$ \\
$\mathrm{O}$ & $1.47 E+00$ & $6.02 E-02$ & $1.43 E+00$ & $5.88 E-02$ & $1.42 E+00$ & $5.84 E-02$ & $1.44 E+00$ & $5.89 E-02$ \\
$\mathrm{Ni}$ & $0.00 E+00$ & $0.00 E+00$ & $9.81 E-02$ & $1.86 E-03$ & $7.73 E-02$ & $1.47 E-03$ & $5.79 E-02$ & $1.10 E-03$ \\
$\mathrm{~Pb}$ & $0.00 E+00$ & $0.00 E+00$ & $0.00 E+00$ & $0.00 E+00$ & $4.89 E-02$ & $5.09 E-04$ & $9.77 E-02$ & $1.02 E-03$ \\
& 2.64 & $\mathbf{0 . 1 1 3 4}$ & 2.67 & $\mathbf{0 . 1 1 2 4}$ & 2.67 & $\mathbf{0 . 1 1 1 2}$ & 2.71 & $\mathbf{0 . 1 1 1 8}$ \\
\hline
\end{tabular}

(b)

\begin{tabular}{lcccccc}
\hline Ele. & & $\mathrm{S}_{5}$ & \multicolumn{2}{c}{$\mathrm{S}_{6}$} & & $\mathrm{~S}_{7}$ \\
& $\mathrm{PD}$ & & $\Sigma_{R}\left(\mathrm{~cm}^{-1}\right)$ & $\mathrm{PD}$ & $\Sigma_{R}\left(\mathrm{~cm}^{-1}\right)$ & $\Sigma_{R}\left(\mathrm{~cm}^{-1}\right)$ \\
\hline $\mathrm{Na}$ & $5.72 E-01$ & $1.95 E-02$ & $5.68 E-01$ & $1.94 E-02$ & $5.73 E-01$ & $1.95 E-02$ \\
$\mathrm{~B}$ & $5.38 E-01$ & $3.09 E-02$ & $5.34 E-01$ & $3.07 E-02$ & $5.39 E-01$ & $3.10 E-02$ \\
$\mathrm{O}$ & $1.44 E+00$ & $5.89 E-02$ & $1.44 E+00$ & $5.89 E-02$ & $1.43 E+00$ & $5.84 E-02$ \\
$\mathrm{Ni}$ & $3.83 E-02$ & $7.28 E-04$ & $1.90 E-02$ & $3.61 E-04$ & $0.00 E+00$ & $0.00 E+00$ \\
$\mathrm{~Pb}$ & $1.45 E-01$ & $1.51 E-03$ & $1.92 E-01$ & $2.00 E-03$ & $2.43 E-01$ & $2.53 E-03$ \\
& 2.73 & $\mathbf{0 . 1 1 1 6}$ & 2.75 & $\mathbf{0 . 1 1 1 3}$ & 2.78 & $\mathbf{0 . 1 1 1 5}$ \\
\hline
\end{tabular}

PD: partial density.

slight variation of $\mu / \rho$ of all the selected borate glass samples at particular photon energy. It is due to the reason that photoelectric absorption is dependent on photon energy and atomic number as $Z$ of the elements and $Z^{4.5} / E^{3.5}$. All the borate glass samples under investigation contain different constituent elements $\left({ }_{5} \mathrm{~B},{ }_{8} \mathrm{O},{ }_{11} \mathrm{Na},{ }_{28} \mathrm{Ni}\right.$, and $\left.{ }_{82} \mathrm{~Pb}\right)$ with different weight fractions of elements. The slight differences in the weight fraction of elements result in insignificant variation of $\mu / \rho$ values in photoelectric absorption region.

With increase in photon energy (above $100 \mathrm{keV}$ ), the reduction rate of the $\mu / \rho$ is observed to be very slow $\left(10^{-1}\right.$ to $10^{-2}$ ). It was observed that the variation is negligible between 0.5 and $5 \mathrm{MeV}$ where Compton scattering dominates. It is because the interaction cross-section is linearly dependent on $Z$. With further increase in photon energy (above $50 \mathrm{MeV}$ ), it was found that the $\mu / \rho$ values start increasing and become constant at around $100 \mathrm{MeV}$. This is because the pair production process in nuclear field, $\mu / \rho_{(\mathrm{npp})}$, and electron field, $\mu / \rho_{(\mathrm{epp})}$, starts at threshold energies of $1.022 \mathrm{MeV}$ and 2.044 MeV and thereafter increases with increase in the incident photon energy. In this high-energy region, a slight variation at particular incident photon energy was again observed due to their different chemical compositions. It may be due to the cross-sections for pair production process in nuclear field and for triplet production depending on atomic numbers $Z^{2}$ and $Z$, respectively. It is to be noted that although pair production processes initiate at photon energy $1.022 \mathrm{MeV}$, they require more incident photon energy to overcome Compton scattering.

3.2. HVL and TVL Values. The variation of half-value layer, HVL, and tenth-value layer, TVL, of the borate glass samples with photon energy ranging from $1 \mathrm{keV}$ to $100 \mathrm{GeV}$ is shown in Figures 2 and 3. We have plotted HVL and TVL of ordinary (OR), hematite-serpentine (HS), ilmenite-limonite (IL), basalt-magnetite (BM), and ilmenite (IT) [22] along with borate glass samples for comparison.

3.3. Effective Atomic Numbers. The variation of effective atomic numbers, $Z_{P \text { Ieff }}$, for total photon interaction and 


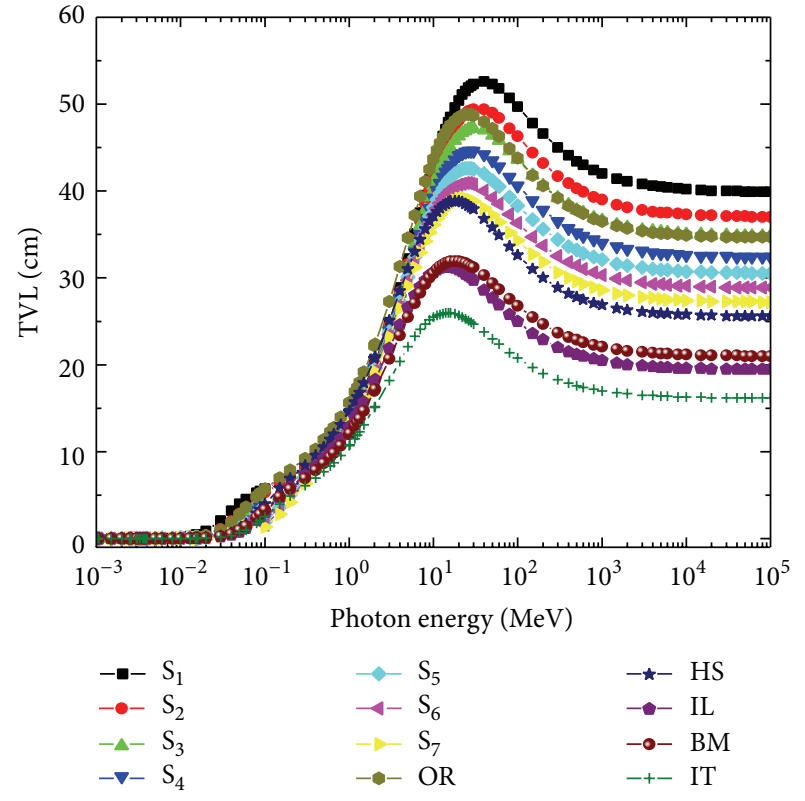

FIgURE 3: Variation of tenth-value layer of the borate glasses containing $\mathrm{PbO}$ and $\mathrm{NiO}$ with photon energy for range $1 \mathrm{keV}$ to $100 \mathrm{GeV}$.

noncoherent interaction of the borate glass samples for photon energy ranging from $1 \mathrm{keV}$ to $100 \mathrm{GeV}$ is shown in Figures 4(a) and 4(b). The average effective atomic numbers, $\langle Z\rangle$, lower and upper values of effective atomic numbers at energies $10^{-3}, 10^{-2}, 10^{-1}, 10^{0}, 10^{1}, 10^{2}, 10^{3}, 10^{4}$, and $10^{5}$ are given in Table 3. At low-energy range $(0.01 \mathrm{MeV}<E<0.05 \mathrm{MeV})$, the maximum value of $Z_{\text {PIeff }}$ was found. At intermediate energies $(0.05 \mathrm{MeV}<E<5 \mathrm{MeV})$, where Compton scattering is the main photon interaction process, $Z_{P I \text { Iff }}$ is approximately equal to the arithmetic mean of the atomic number calculated from the chemical formula of the glass samples, $\langle Z\rangle=$ $(1 / n) \sum_{i} n_{i} z_{i}$. At high energies, $(E>50 \mathrm{MeV}), Z_{P I \text { eff }}$ is again constant but smaller than in the low-energy region. It is observed that there is a good agreement between $Z_{P I \text { eff }}$ at $10 \mathrm{MeV}$ (Table 3) and the mean atomic number, $\langle Z\rangle$, derived from the chemical composition of the glass samples, where Compton scattering is the main photon interaction process.

3.4. Effective Electron Densities. The variation of effective electron densities, $N_{e, \text { eff }}$, for total interaction and noncoherent interaction of the borate glass samples with photon energy ranging from $1 \mathrm{keV}$ to $100 \mathrm{GeV}$ is shown in Figures 5(a) and 5(b). The average effective electron density, $\left\langle N_{e}\right\rangle$, lower and upper values of effective electron densities at specific energies as $10^{-3}, 10^{-2}, 10^{-1}, 10^{0}, 10^{1}, 10^{2}, 10^{3}, 10^{4}$, and $10^{5}$ are given in Table 4 . The variations of $N_{e \text {,eff }}$ with photon energy for total interaction processes (Figures 5(a) and 5(b)) were similar to that of $Z_{P I \text { Ieff }}$ and can be explained in similar manner.

3.5. Macroscopic Fast Neutron Removal Cross-Section. The macroscopic fast neutron removal cross-sections $\Sigma_{R}\left(\mathrm{~cm}^{-1}\right)$ of the borate glass samples are given in Table 5. It was

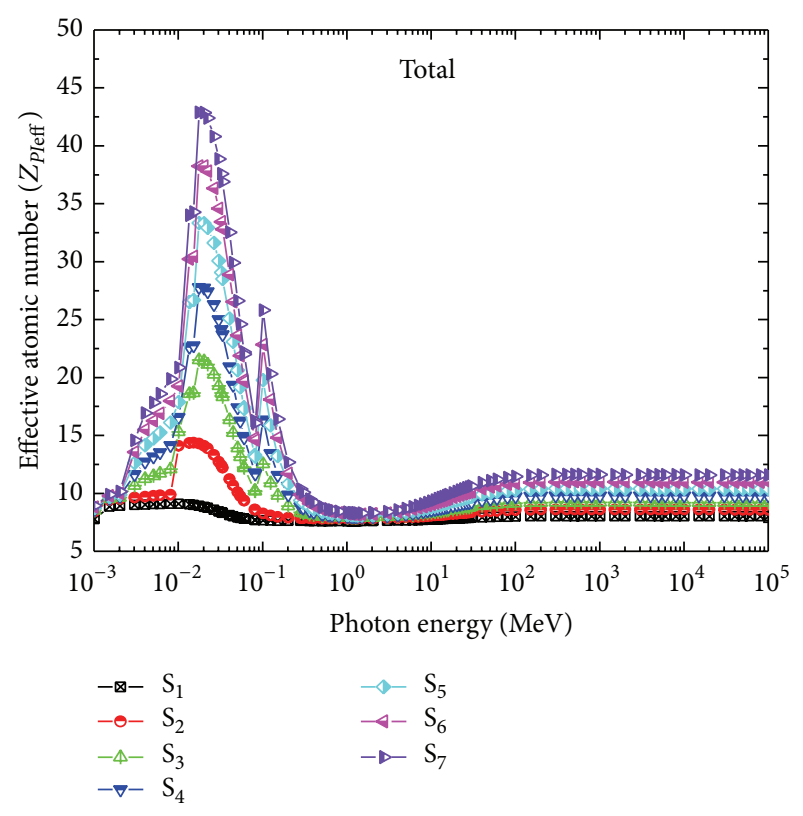

(a)

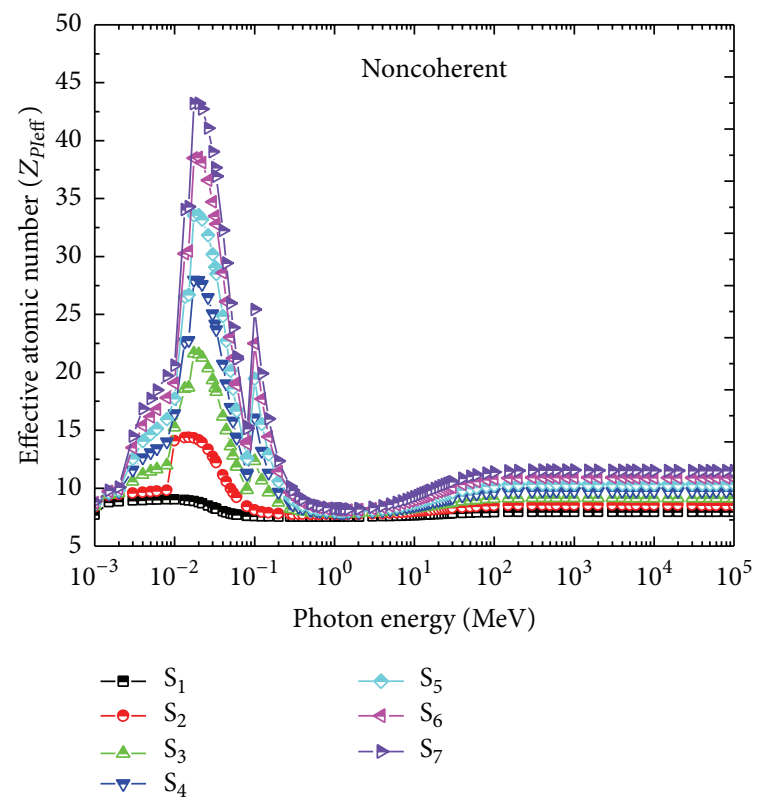

(b)

FIGURE 4: Variation of effective atomic numbers of the borate glasses containing $\mathrm{PbO}$ and $\mathrm{NiO}$ with photon energy for range $1 \mathrm{keV}$ to $100 \mathrm{GeV}$.

observed that the $\Sigma_{R}$ was highest (0.1134) for $\mathrm{S}_{1}$ whereas all the remaining borate glasses range from 0.1112 to 0.1118 . The highest value of $\Sigma_{R}$ for $S_{1}$ was observed due to zero contribution of $\mathrm{Pb}$ and $\mathrm{Ni}$ elements. It can be concluded that borate glass sample $\left(S_{1}\right)$ is a superior neutron shielding material. Moreover, the borate glass alone may not be suitable for gamma ray shielding; therefore borate glasses containing $\mathrm{PbO}$ and $\mathrm{NiO}$ are suitable glass shielding materials for gamma ray and neutron. Since oxide containing glasses 


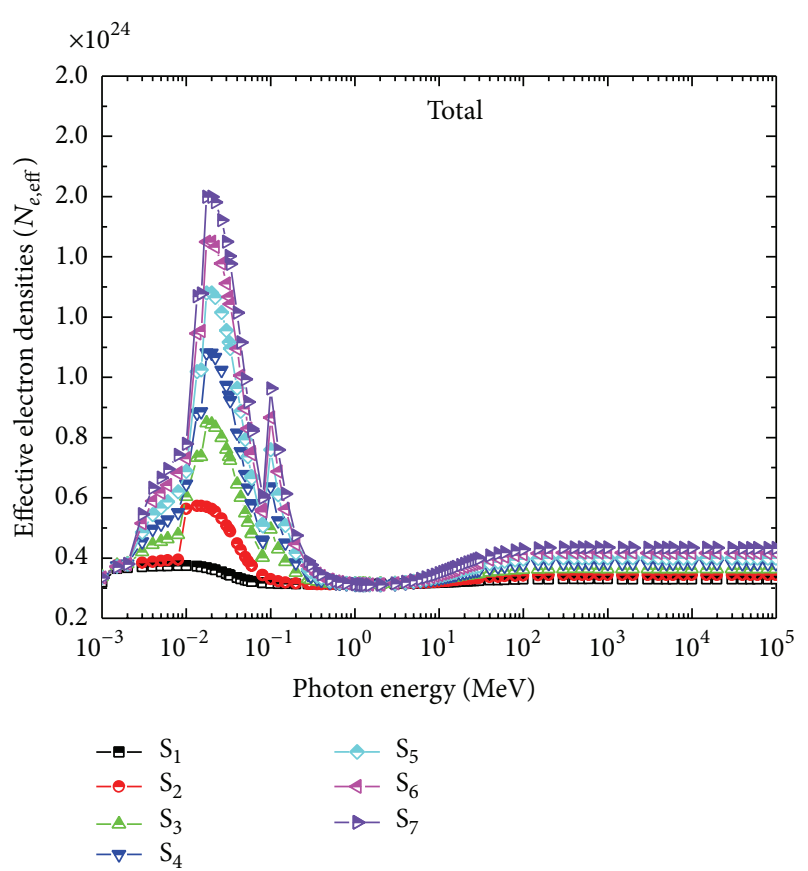

(a)

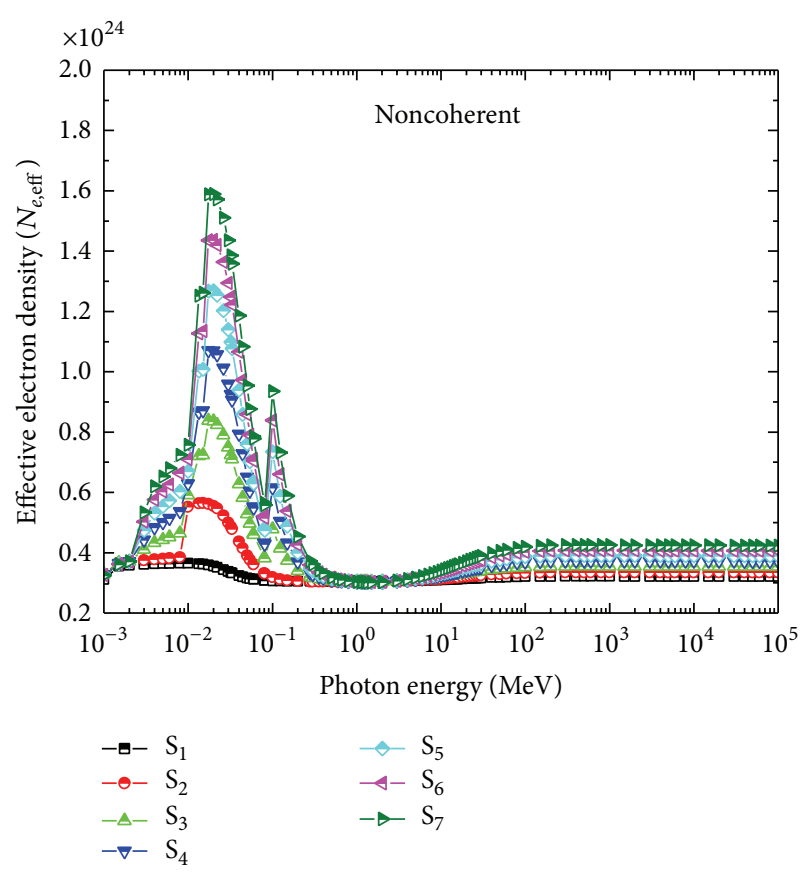

(b)

Figure 5: Variation of effective electron densities of the borate glasses containing $\mathrm{PbO}$ and $\mathrm{NiO}$ with photon energy for range $1 \mathrm{keV}$ to $100 \mathrm{GeV}$.

are having roughly constant $\Sigma_{R}$, borate glass containing $10 \% \mathrm{PbO}\left(\mathrm{S}_{7}\right)$ would be preferable gamma ray as well as neutron shielding. The $\Sigma_{R}$ value of borate glass sample $\left(S_{1}\right)$ was found to be higher than ordinary concrete whereas other borate glass samples $\left(S_{2} \cdots S_{7}\right)$ were lower than it.

\section{Conclusions}

In the present investigation, the mass attenuation coefficients, $\mu / \rho$, half-value layer, HVL, tenth-value layer, TVL, effective atomic numbers, $Z_{P I \text { eff }}$, and effective electron densities, $N_{e \text {,eff }}$, of borate glass samples containing $\mathrm{PbO}$ and $\mathrm{NiO}$ were calculated for photon energy $1 \mathrm{keV}$ to $100 \mathrm{GeV}$. The macroscopic fast neutron removal cross-sections were calculated for neutron energy 2-12 MeV. These parameters were found to be varying with the photon energy and chemical compositions of the glass samples. These results shall be useful for shielding applications against gamma ray and neutron.

\section{Conflict of Interests}

The authors declare that there is no conflict of interests regarding the publication of this paper.

\section{References}

[1] W. S. Rothwell, Radiation Shielding Window Glasses, Bull. PE50, Coming Glass Works, Coming, New York, NY, USA, 1958.

[2] K. J. Singh, N. Singh, R. S. Kaundal, and K. Singh, "Gammaray shielding and structural properties of $\mathrm{PbO}-\mathrm{SiO} 2$ glasses," Nuclear Instruments and Methods in Physics Research B, vol. 266, no. 6, pp. 944-948, 2008.

[3] G. Samuel and S. Alexander, Nuclear Reactor Engineering, vol. 1, 4th edition, 2004.

[4] J. Wood, Computational Methods in Reactor Shielding, Pergamon Press, New York, NK, USA, 1982.

[5] M. J. Berger, J. H. Hubbell, S. M. Seltzer et al., "XCOM: photon cross sections database," NIST Standard Reference Database (XGAM) NBSIR 87-3597, 2010, http://www.nist.gov/pml/data /xcom/index.cfm.

[6] L. Gerward, N. Guilbert, K. B. Jensen, and H. Levring, "WinXCom-a program for calculating X-ray attenuation coefficients," Radiation Physics and Chemistry, vol. 71, no. 3-4, pp. 653-654, 2004.

[7] J. Kaewkhao and P. Limsuwan, "Mass attenuation coefficients and effective atomic numbers in phosphate glass containing $\mathrm{Bi} 2 \mathrm{O} 3, \mathrm{PbO}$ and $\mathrm{BaO}$ at $662 \mathrm{keV}$," Nuclear Instruments and Methods in Physics Research A, vol. 619, no. 1-3, pp. 295-297, 2010.

[8] K. Kirdsiri, J. Kaewkhao, A. Pokaipisit, W. Chewpraditkul, and P. Limsuwan, "Gamma-rays shielding properties of xPbO:(100 - $x) \mathrm{B}_{2} \mathrm{O}_{3}$ glasses system at $662 \mathrm{keV}$,' Annals of Nuclear Energy, vol. 36, no. 9, pp. 1360-1365, 2009.

[9] K. Kirdsiri, J. Kaewkhao, N. Chanthima, and P. Limsuwan, "Comparative study of silicate glasses containing $\mathrm{Bi}_{2} \mathrm{O}_{3}, \mathrm{PbO}$ and $\mathrm{BaO}$ : Radiation shielding and optical properties," Annals of Nuclear Energy, vol. 38, no. 6, pp. 1438-1441, 2011.

[10] S. Singh, A. Kumar, D. Singh, K. S. Thind, and G. S. Mudahar, "Barium-borate-flyash glasses: As radiation shielding materials," Nuclear Instruments and Methods in Physics Research B, vol. 266, no. 1, pp. 140-146, 2008.

[11] N. Chanthima, J. Kaewkhao, and P. Limsuwan, "Study of photon interactions and shielding properties of silicate glasses containing $\mathrm{Bi} 2 \mathrm{O} 3, \mathrm{BaO}$ and $\mathrm{PbO}$ in the energy region of $1 \mathrm{keV}$ to $100 \mathrm{GeV}$,' Annals of Nuclear Energy, vol. 41, pp. 119-124, 2012.

[12] W. Weyl, Coloured Glasses, Society of Glass Technology, London, UK, 1951. 
[13] A. I. Fawazi, A. A. El-Sayes, A. A. El-Latif, and M. ElDesoky, "Borate glass with lead and Nickel oxides for radiation attenuation," Abhath Al-Yarmouk, vol. 15, no. 2, pp. 195-205, 2006.

[14] S. R. Manohara, S. M. Hanagodimath, K. S. Thind, and L. Gerward, "On the effective atomic number and electron density: a comprehensive set of formulas for all types of materials and energies above $1 \mathrm{keV}$," Nuclear Instruments and Methods in Physics Research B, vol. 266, no. 18, pp. 3906-3912, 2008.

[15] V. P. Singh and N. M. Badiger, "Gamma ray and neutron shielding properties of some soils samples: buildup factors and attenuation coefficients," Indian Journal of Pure and Applied Physics. In press.

[16] V. P. Singh and N. M. Badiger, "The Study on gamma-ray and neutron shielding factors of fly-ash bricks materials," Journal Radiological Protection, vol. 34, pp. 89-101, 2014.

[17] V. P. Singh, N. M. Badiger, N. Chanthima, and J. Kaewkhao, "Evaluation of gamma-ray exposure buildup factors and neutron shielding for bismuth borosilicate glasses,", Radiation Physics and Chemistry, vol. 98, pp. 14-21, 2014.

[18] V. P. Singh, N. M. Badiger, and M. E. Medhat, "Assessment of exposure build-up factors of some oxide dispersion strengthened steels applied in modern nuclear engineering and designs," Nuclear Engineering and Design, vol. 270, pp. 90-100, 2014.

[19] V. P. Singh, N. M. Badiger, and A. M. El-Khayatt, "Study on gamma-ray exposure buildup factors of and fast neutron shielding of some building materials," Radiation Effects and Defects in Solids. In press.

[20] M. F. Kaplan, Concrete Radiation Shielding, Longman Scientific and Technology, England, UK, 1989.

[21] A. B. Chilten, J. K. Shultis, and R. E. Faw, Principle of Radiation Shielding, Prentice-Hall, Englewood, Ill, USA, 1984.

[22] I. I. Bashter, "Calculation of radiation attenuation coefficients for shielding concretes," Annals of Nuclear Energy, vol. 24, no. 17, pp. 1389-1401, 1997. 

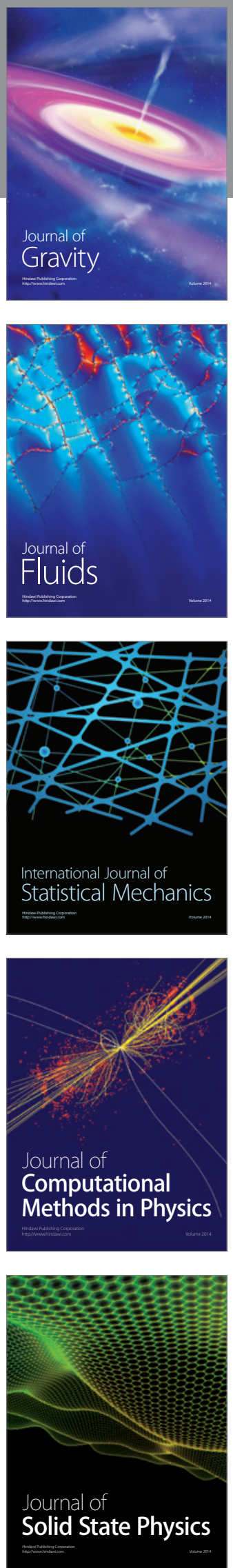

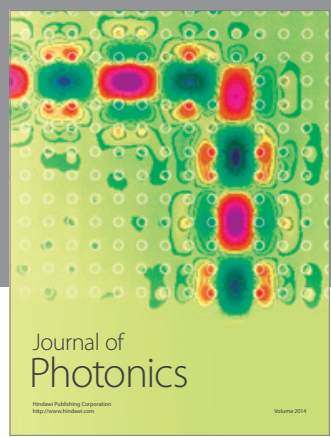

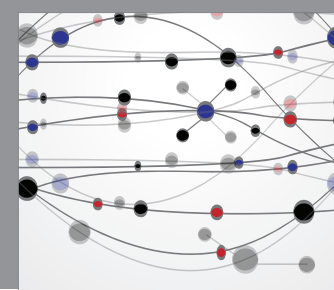

The Scientific World Journal

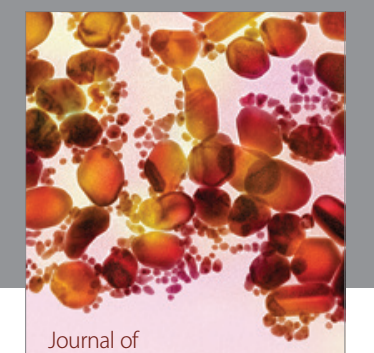

Soft Matter
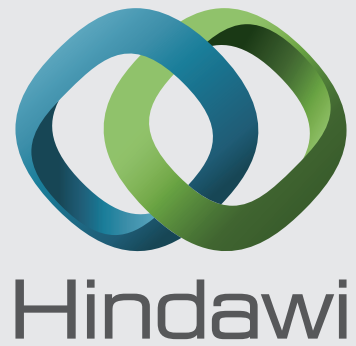

Submit your manuscripts at

http://www.hindawi.com
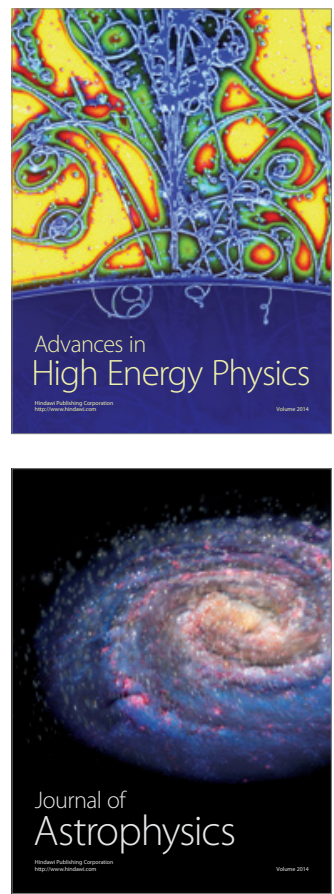
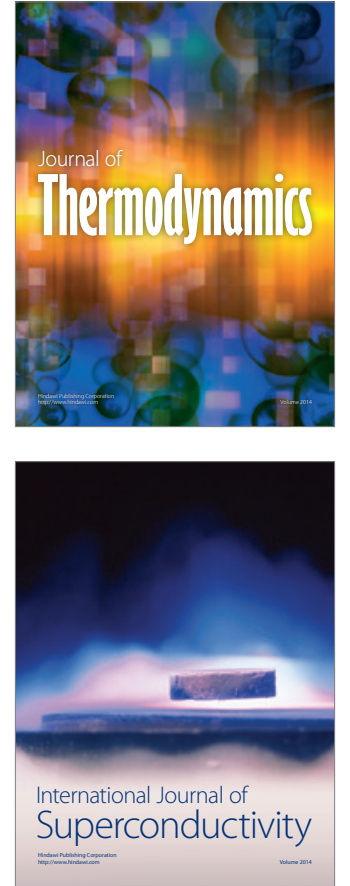
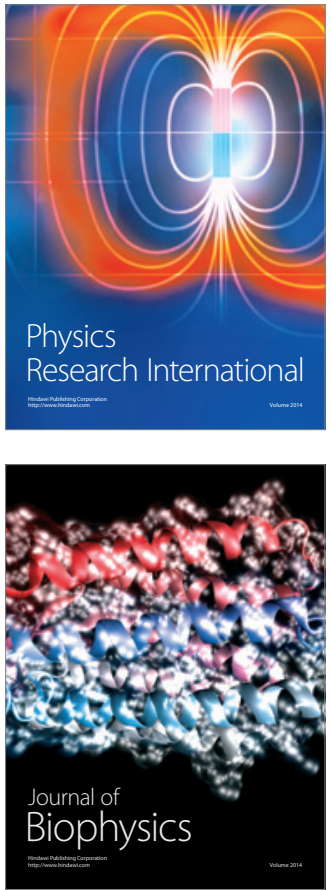
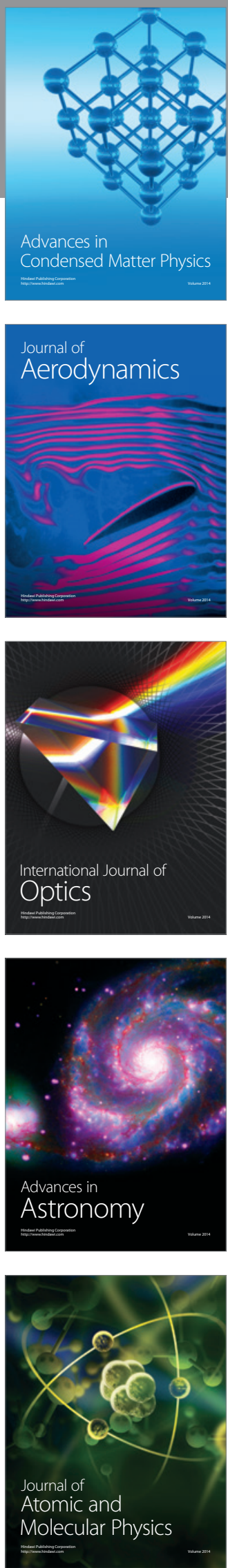